\title{
Metabolic response of Scapharca subcrenata to heat stress using GC/MS-based metabolomics
}

\author{
Yazhou Jiang ${ }^{1}$, Haifeng Jiao ${ }^{2}$, Peng Sun ${ }^{1}$, Fei Yin ${ }^{3}$, Baojun Tang ${ }^{\text {Corresp. } 1}$ \\ ${ }^{1}$ East China Sea Fisheries Research Institute, Chinese Academy of Fishery Sciences, Shanghai, China \\ 2 Ningbo Academy of Ocean and Fishery, Ningbo, Zhejiang, China \\ 3 Key Laboratory of Applied Marine Biotechnology, Ministry of Education, Ningbo University, Ningbo, Zhejiang, China \\ Corresponding Author: Baojun Tang \\ Email address: bjtang@yeah.net
}

Marine mollusks are commonly subjected to heat stress. To evaluate the effects of heat stress on the physiological metabolism of the ark shell Scapharca subcrenata, clams were exposed to different high temperatures $\left(24,28\right.$, and $\left.32^{\circ} \mathrm{C}\right)$ for $72 \mathrm{~h}$. The oxygen consumption and ammonia excretion rates were measured at 2, 12, 24, 48, and $72 \mathrm{~h}$. The results indicated that the metabolic rates of the ark shell significantly increased with increasing heat stress, accompanied by mortalities in response to prolonged exposure. A metabolomics approach based on gas chromatography coupled with mass spectrometry was further applied to assess the changes of metabolites in the mantle of the ark shell at $32{ }^{\circ} \mathrm{C}$. Moreover, multivariate and pathway analyses were conducted for the different metabolites. The results showed that the heat stress caused changes in energy metabolism, amino acid metabolism, osmotic regulation, carbohydrate metabolism, and lipid metabolism through different metabolic pathways. These results are consistent with the significant changes of oxygen consumption rate and ammonia excretion rate. The present study contributes to the understanding of the impacts of heat stress on intertidal bivalves and elucidates the relationship between individual-level responses and underlying molecular metabolic dynamics. 
1 Metabolic response of Scapharca subcrenata to heat stress using GC/MS-based

2 metabolomics

3

4

6

7

8 China

92 Ningbo Academy of Ocean and Fishery, Ningbo 315012, China

10

11

12

13

14

15

16

17

18

19

20

21

22

23

24

25

26

27

28

29

30

31

32

33

34

35

36

37

38

Yazhou Jiang ${ }^{1}$, Haifeng Jiao ${ }^{2}$, Peng Sun ${ }^{1}$, Fei Yin ${ }^{3}$, Baojun Tang ${ }^{1 *}$ 315211, China

Corresponding Author:

Baojun Tang ${ }^{1}$

No.300, Jungong Road, Shanghai, China

Email address: bjtang@yeah.net

\section{Abstract} molecular metabolic dynamics.

\section{Introduction}

${ }^{1}$ East China Sea Fisheries Research Institute, Chinese Academy of Fishery Sciences, Shanghai 200090,

${ }^{3}$ Key Laboratory of Applied Marine Biotechnology, Ministry of Education, Ningbo University, Ningbo

Marine mollusks are commonly subjected to heat stress. To evaluate the effects of heat stress on the physiological metabolism of the ark shell Scapharca subcrenata, clams were exposed to different high temperatures $\left(24,28\right.$, and $\left.32{ }^{\circ} \mathrm{C}\right)$ for $72 \mathrm{~h}$. The oxygen consumption and ammonia excretion rates were measured at $2,12,24,48$, and $72 \mathrm{~h}$. The results indicated that the metabolic rates of the ark shell significantly increased with increasing heat stress, accompanied by mortalities in response to prolonged exposure. A metabolomics approach based on gas chromatography coupled with mass spectrometry was further applied to assess the changes of metabolites in the mantle of the ark shell at $32{ }^{\circ} \mathrm{C}$. Moreover, multivariate and pathway analyses were conducted for the different metabolites. The results showed that the heat stress caused changes in energy metabolism, amino acid metabolism, osmotic regulation, carbohydrate metabolism, and lipid metabolism through different metabolic pathways. These results are consistent with the significant changes of oxygen consumption rate and ammonia excretion rate. The present study contributes to the understanding of the impacts of heat stress on intertidal bivalves and elucidates the relationship between individual-level responses and underlying

Temperature is one of the more prominent abiotic factors that influences the physiological metabolism of animals and determines the ecological niche of a species (Pörtner et al., 2006; Pörtner, 2010; Ezgeta-Balić et al., 2011). Temperature has also become an increasingly severe source of environmental stress due to the increase of seawater temperature as a result of global 
40 climate changes. The global water surface temperature has increased by approximately $0.7^{\circ} \mathrm{C}$ 41 during the last century (Hansen et al., 2006) and a continued increase has been predicted (Wang 42 et al., 2015). In response to environmental changes, organisms typically adjust their metabolic 43 physiology to adapt to new energy requirements (Cheung \& Lam, 1995; Lagerspetz, 2006; 44 Zhang et al., 2017). It has been reported that temperature can affect the metabolic rates of marine invertebrates, thus influencing the energy available for growth (González et al., 2002). Intertidal

46

47 48

49

50 51

52

53

54 55 56

57

58

59

60

61

62

63

64

65

66

67

68

69

bivalves frequently face extreme heat stress (Han et al., 2013), and form reliable models to investigate the adaptations to highly fluctuating environments (Davenport \& Davenport, 2005; Wang et al., 2015). Thus, studying the underlying metabolic alterations can help to understand the physiological changes that happen in bivalves in response to thermal stress.

The effects of heat stress on the energy metabolism of marine bivalves have been widely studied in many species (Sokolova et al., 2012), such as Mytilus galloprovincialis (Anestis et al., 2007),

the limpet Cellana toreuma (Han et al., 2013), Mercenaria mercenaria (Ivanina et al., 2013) and the eastern oyster Crassostrea virginica (Casas et al., 2018). Among the many indicators of physiological responses to thermal challenge, the respiration behavior and individual-level metabolic rates (especially oxygen consumption rate) have been widely used to assess the physiological state in response to stress tolerance or adaptation during exposure to heat stress (Sobral \& Widdows, 1997; Saucedo et al., 2004; Sara, 2008; Dowd \& Somero, 2013; Frisk Steffensen \& Skov, 2013; Wang et al., 2015; Casas et al., 2018). Successful persistence or tolerance requires molecular adaptations to compensate for the impaired metabolism, triggered by changes of temperature (Lim et al., 2016). Moreover, investigating the correlation between individual-level responses and molecular changes is useful toward a better understanding of the responses and regulating mechanisms from an overall perspective. Recently, research has increasingly focused on molecular adaptation or tolerance of marine bivalves to heat stress, and new analytic techniques, such as transcriptomics (Lim et al., 2016; Nie et al., 2017; Yang et al., 2017; Juárez et al., 2018; Zhang et al., 2019) and metabolomics (Ellis et al., 2014; Digilio et al., 2016), were used. The mantle tissue of mollusks has multiple functions, which include ligament secretion and sensorial activities; moreover, this tissue is very responsive to external stimuli (Artigaud et al., 2015). The mantle tissue has been used for transcriptome, proteomic, or metabolomic analyses in many studies (Artigaud et al., 2014, 2015; Wei et al., 2015).

Peer) reviewing PDF | (2019:09:40921:1:0:NEW 29 Nov 2019) 
70 Metabolomics refers to the systematic study of chemical processes that involve metabolites. By

71 measuring the levels of endogenous low-molecular-weight metabolites, metabolomics can be

72 used to identify biomarkers that are indicative of physiological responses of living samples to

73 specific environmental or culture conditions (Alfaro \& Young, 2016). Many analytical platforms

74 have been used for metabolomics, including raman spectroscopy, infrared spectroscopy, nuclear

75 magnetic resonance (NMR) and many mass (MS) spectrometry techniques, of which NMR and

76 MS are the most widely applied analytical tools for their sufficient high throughput and

77 resolution properties (Young \& Alfaro, 2016). Gas chromatography coupled with mass

78 spectrometry (GC/MS) is a well-established analytical method that can provide a comprehensive

79 and systematic understanding of all metabolites in biological samples (Tsugawa et al., 2011;

80 Nguyen \& Alfaro, 2019a). GC/MS-based metabolomics has been widely applied to study the

81 physiological responses of aquatic organisms to environmental stressors, including pathogen

82 infection, water contaminants and aerial exposure, and many metabolites and associated

83 pathways have been successfully identified (Guo et al. 2014; Ji et al., 2015; Chen et al., 2015;

84 Nguyen et al., 2018a,2018c, 2018d; Alfaro, Nguyen \& Mellow, 2019).

85 The ark shell Scapharca subcrenata inhabits the muddy sediments of the shallow coasts of

86 China, Japan, and Korea (Nakamura, 2005) and is widely cultured and consumed as a popular

87 foodstuff in China and Korea (Jin, Ahn \& Je, 2018). Due to its large geographic distribution, ark

88 shell populations are exposed to strongly differing thermal conditions such as diurnal

89 temperature fluctuations and extreme high temperature during summer. For example, the water

90 temperature of the S. subcrenata habitat Xiangshan Bay (China) varies between $6.7^{\circ} \mathrm{C}$ and 33.0

$91{ }^{\circ} \mathrm{C}$ (You \& Jiao, 2011). However, little information is available on the physiological responses of

92 S. subcrenata to such pronounced heat stress.

93 Understanding the response of organisms to heat stress requires an in-depth understanding of

94 both their acute responses and their compensatory acclimatization responses to the elevated

95 temperature (Pörtner et al., 2006). In the present study, the oxygen consumption and ammonia

96 excretion rates of $S$. subcrenata in response to heat stress were measured. Furthermore, the

97 metabolic profile in the mantle was characterized using GC/MS to identify biomarkers for the

98 responses to heat stress.

99

100 Materials \& Methods 
101 Animals and heat stress

102 Adult S. subcrenata individuals were collected in Xiangshan Bay, East China Sea in November

103 by a fishing trawler and transported in buckets containing seawater to the laboratory at the

104 seaside of the Bay. The water temperature at the sampling site was $19.6^{\circ} \mathrm{C}$. The clams were

105 maintained in a glass aquarium at $20 \pm 0.5^{\circ} \mathrm{C}$, provided with constant aeration. To minimize the

106 effects of body size on metabolic responses to heat stress, only individuals with similar shell

107 length were used $(28.11 \pm 1.36 \mathrm{~mm})$.

108 The clams were randomly divided into four groups ( 70 clams for 20,24 , and $28{ }^{\circ} \mathrm{C}$ treatment, 109 and 80 clams for $32{ }^{\circ} \mathrm{C}$ treatment) and were transferred to four $60-\mathrm{L}$ water baths, filled with

110 aerated seawater, that were connected to a temperature controller. The seawater temperature was 111 gradually increased from $20{ }^{\circ} \mathrm{C}$ to 24,28 , and $32{ }^{\circ} \mathrm{C}$ over $2 \mathrm{~h}, 4 \mathrm{~h}$, and $6 \mathrm{~h}$ periods, respectively.

112 The temperature was then maintained constant for further $72 \mathrm{~h}$. At 2, 12, 24, 48, and $72 \mathrm{~h}$ of

113 exposure to different heat stress levels, both the oxygen consumption rate and ammonia

114 excretion rate of $S$. subcrenata were measured. During the experiment, the seawater in each tank 115 was renewed daily.

116 Based on the results of oxygen consumption and ammonia excretion measurements, six

117 replicates of mantle samples were taken $2 \mathrm{~h}$ and $24 \mathrm{~h}$ after the seawater temperature was

118 gradually increased from 20 to $32^{\circ} \mathrm{C}$. All samples were immediately frozen in liquid nitrogen

119 and stored at $-80{ }^{\circ} \mathrm{C}$ for further metabolomic analysis.

\section{Measurement of oxygen consumption rate and ammonia excretion rate}

121 Both the oxygen consumption and ammonia excretion rates were determined in a $1500 \mathrm{~mL}$ glass

122 respiration chamber. Two clams were sealed for $2 \mathrm{~h}$ in a chamber filled with oxygen saturated

123 seawater. The oxygen concentration in this chamber was measured according to standard

124 procedure (Stickland \& Parsons, 1968). The $\mathrm{NH}_{4}{ }^{+}-\mathrm{N}$ concentration was determined with the

125 phenol-hypochlorite method (Solorzano, 1969). Individual clams were sampled for measurement

126 at $1,11,23,47$, and $71 \mathrm{~h}$ after heat stress challenge. Since each measurement cycle spanned a

127 two-hour period, the measured values represent the averages of 1-3, 11-13, 23-25, 47-49, and 71-

$12873 \mathrm{~h}$, respectively. The results are presented as the rates at 2, 12, 24, 48, and $72 \mathrm{~h}$. Each

129 measurement was performed in three replicates and a chamber without clams served as control.

130 After measurements, the dry weight of the soft parts of each clam was determined after drying at $13165^{\circ} \mathrm{C}$ for $24 \mathrm{~h}$. 
132

\section{Metabolite extraction}

134 For metabolite extraction, $30 \mathrm{mg}$ accurately weighed wet sample was transferred into a $1.5-\mathrm{mL}$

135 Eppendorf tube with two small steel balls (with diameters of $1.50 \mathrm{~mm}$ ) for crushing. An aliquot 136 of $20 \mu \mathrm{L}$ of 2-chloro-1-phenylalanine $(0.3 \mathrm{mg} / \mathrm{mL})$, dissolved in methanol as internal standard, 137 and $600 \mu \mathrm{L}$ mixture of methanol and water (4/1, vol/vol) were added to each sample. All samples 138 were cooled to $-80^{\circ} \mathrm{C}$ for $2 \mathrm{~min}$ and then ground at $60 \mathrm{~Hz}$ for $2 \mathrm{~min}$. After vortexing, the ground 139 samples were ultrasonicated for $10 \mathrm{~min}$ at ambient temperature and cooled to $-20^{\circ} \mathrm{C}$ for $30 \mathrm{~min}$. 140 The samples were then centrifuged at $13000 \mathrm{rpm}, 4^{\circ} \mathrm{C}$ for $15 \mathrm{~min}$ (Eppendorf Centrifuge 5427 141 R, Hamburg, Germany). The supernatant $(400 \mu \mathrm{L})$ was dried in a freeze concentration 142 centrifugal dryer (Christ RVC 2-33IR, Osterode, Germany), and $80 \mu \mathrm{L}$ of $15 \mathrm{mg} / \mathrm{mL}$ 143 methoxylamine hydrochloride in pyridine was added subsequently. The resulting mixture was 144 vortexed for $2 \mathrm{~min}$ and incubated at $37^{\circ} \mathrm{C}$ for $90 \mathrm{~min}$. Then, $80 \mu \mathrm{L}$ of 145 bis(trimethylsilyl)trifluoroacetamide (BSTFA) (with 1\% trimethylchlorosilane) (TMCS) and 20 $146 \mu \mathrm{L}$ n-hexane was added, which was vortexed for $2 \mathrm{~min}$, and then derivatized at $70{ }^{\circ} \mathrm{C}$ for $60 \mathrm{~min}$. 147 The resultant mixture was exposed to ambient temperature for $30 \mathrm{~min}$ before GC-MS analysis. 148 Quality control (QC) samples were prepared by pooling all samples together, with the volume 149 same as the analytic samples, and then analyzed using the same method. The QCs were injected 150 at regular intervals (every 10 samples) throughout the analytical process to ensure the 151 reproducibility of the GC-MS measurement.

\section{GC/MS analysis}

153 The derivatized samples were analyzed using an Agilent 7890A gas chromatography system 154 coupled with an Agilent 5975C MSD system (Agilent, Santa Clara, CA, USA). A HP-5MS 155 fused-silica capillary column $(30 \mathrm{~m} \times 0.25 \mathrm{~mm} \times 0.25 \mu \mathrm{m}$, Agilent $)$ was utilized to separate the 156 derivatives. Helium ( $>99.999 \%$ ) was used as carrier gas at a constant flow rate of $6.0 \mathrm{~mL} / \mathrm{min}$

157 through the column. The injector temperature was maintained at $280{ }^{\circ} \mathrm{C}$ and the injection volume 158 was $1 \mu \mathrm{L}$ in splitless mode. The initial oven temperature was $60^{\circ} \mathrm{C}$, was increased to $125^{\circ} \mathrm{C}$ at a 159 rate of $8{ }^{\circ} \mathrm{C} / \mathrm{min}$, to $190^{\circ} \mathrm{C}$ at a rate of $10^{\circ} \mathrm{C} / \mathrm{min}$, to $210^{\circ} \mathrm{C}$ at a rate of $4{ }^{\circ} \mathrm{C} / \mathrm{min}$, to $310{ }^{\circ} \mathrm{C}$ at a rate of $20^{\circ} \mathrm{C} / \mathrm{min}$, and finally, a temperature of $310^{\circ} \mathrm{C}$ was sustained for $8.5 \mathrm{~min}$. The temperatures of the MS quadrupole and ion source (electron impact, EI) were set to 150 and 230 
$162{ }^{\circ} \mathrm{C}$, respectively, and the collision energy was $70 \mathrm{eV}$. Mass data was acquired in full-scan mode 163 (m/z 50-600), and the solvent delay time was set to $5 \mathrm{~min}$.

164 Statistical analysis

165 For the results of oxygen consumption rates and ammonia excretion rates, One-way ANOVA 166 and multiple comparisons were performed with SPSS 11.5 statistical software, and a $P$ value less 167 than 0.05 was considered to be statistically significant.

168 The acquired MS data from GC-MS were analyzed by ChromaTOF software (v4.34, LECO, St 169 Joseph, MI, USA). The metabolites were identified by the Fiehn database using the method 170 described by Mishra et al. (2017). Briefly, after alignment with the Statistic Compare 171 component, the CSV file was obtained with three-dimensional data sets including sample 172 information, peak name, retention time, $\mathrm{m} / \mathrm{z}$, and peak intensities. The internal standard was used 173 for quality control. The internal standards and any identified pseudo positive peaks, such as 174 peaks caused by noise, column bleed, and the BSTFA derivatization procedure, were removed 175 from the data set. Peaks from the same metabolites were combined.

176 The resulting data were normalized to the total peak area of each sample using Excel 2007 177 (Microsoft, USA) and were imported into the SIMCA software package (v14.0, Umetrics, Umeå, 178 Sweden), where principal component analysis (PCA), partial least-squares discriminant analysis 179 (PLS-DA), and orthogonal partial least-squares discriminant analysis (OPLS-DA) were 180 performed. The Hotelling's T2 region, shown as an ellipse in score plots of the models, was used 181 to define the $95 \%$ confidence interval of the modeled variation. The quality of the models was 182 described by the $R^{2} X$ or $R^{2} Y$ and $Q^{2}$ values. $R^{2} X$ or $R^{2} Y$ are defined as the proportion of variance 183 in the data that can be explained by the models and indicates goodness of fit. $Q^{2}$ is defined as the 184 proportion of variance in the data that is predicted by the model and indicates predictability, as 185 calculated by a cross-validation procedure. A default seven-round cross-validation in SIMCA 186 was performed to determine the optimal number of principal components and to avoid model 187 overfitting. The OPLS-DA models were also validated by permutation analysis (200 times).

188 The different metabolites were selected based on the combination of a statistically significant 189 threshold of variable influence on projection (VIP) values obtained from the OPLS-DA model 190 and on $P$ values from a two-tailed Student's t test on the normalized peak areas. Metabolites with 191 VIP values exceeding 1.0 and $P$ values of less than 0.05 were included. 
193 Results

194 Survival rates

195 Enhanced heat stress increased the mortality of experimental clams. The survival rates of $S$.

196 subcrenata exposed to $20,24,28$, and $32{ }^{\circ} \mathrm{C}$ seawater temperature were $97.14 \%, 92.85 \%$,

$19784.28 \%$, and 75\%, respectively. Most mortalities occurred within $24 \mathrm{~h}$ after thermal challenge.

\section{Metabolic rates}

199 After the temperature was increased to $24^{\circ} \mathrm{C}$, the oxygen consumption rate of $S$. subcrenata

200 decreased for $2 \mathrm{~h}$, followed by a significant increase at $24 \mathrm{~h}$ and $48 \mathrm{~h}(P<0.05$ and $P<0.01$,

201 respectively; Fig. 1). After exposure to 28 and $32{ }^{\circ} \mathrm{C}$ stress, the oxygen consumption rates

202 increased significantly at $2,24,48$, and $72 \mathrm{~h}(P<0.05,0.01)$. The increase was not significant

203 for $12 \mathrm{~h}$, although the oxygen consumption rate was still higher than that of the control group.

204 After exposure to heat stress, the ammonia excretion rates of $S$. subcrenata increased first, then

205 decreased, and increased again (Fig. 2). S. subcrenata exposed to heat stress at $24^{\circ} \mathrm{C}$

206 demonstrated higher ammonia excretion at $12 \mathrm{~h}$ compared with the control group $(P<0.01)$. The

207 clams exposed to $28^{\circ} \mathrm{C}$ heat stress showed significantly higher ammonia excretion rates at 2, 12 ,

208 and $72 \mathrm{~h}(P<0.05$ and $P<0.01$, respectively). The ammonia excretion rate of $S$. subcrenata

209 exposed to $32^{\circ} \mathrm{C}$ was significantly higher than that of the control group at 2, 24, 48, and $72 \mathrm{~h}(P$

$210<0.01)$.

211 Metabolic profiles analyzed by GC-MS

212 The typical total ion chromatograms (TIC) of both S. subcrenata mantle samples and quality

213 control samples displayed stable retention times (Fig. 1S). Thus, the TIC could directly reflect

214 the differences of metabolite profiles among groups. The PCA score plot is shown in Fig. 3. The

215 three groups were generally separated, especially the control group and the M-24 group. The $R^{2} X$

216 value of the PCA model, representing the explained variance for the groups, was 0.484 . All

217 groups were within the Hotelling ellipse of 95\% confidence, indicating that the analyzed samples

218 contained no outlier.

219 Further supervised pattern recognitions, PLS-DA, and OPLS-DA, were performed to obtain a

220 better explanation of different metabolic patterns (Fig. 4). The classification parameters for the

221 PLS-DA and OPLS-DA model are shown in Table 1, indicating the robustness of the models.

222 The pairwise groups in each subplot were clearly separated into two sides of the Hotelling T2

223 ellipse, indicating that both models could identify differences among groups. 


\section{Metabolite identification and comparison}

225 A total of 345 metabolites were identified, including amino acids (e.g. aspartic acid, glutamic 226 acid, and histidine), organic acids (e.g. creatine, gluconic acid, malic acid, and oxalic acid), and 227 energy metabolism-related metabolites (e.g. glucose-6-phosphate and erythrose). At $2 \mathrm{~h}$ after 228 heat stress, 39 metabolites showed significant changes, including 13 downregulated and 26 229 upregulated metabolites (Table 1S). At 24 h, 90 metabolites showed significant changes, 230 including 39 downregulated and 51 upregulated (Table 2S).

231 Among metabolites that showed significant changes, the relative concentration of glucose-6232 phosphate presented a continuous decrease at 2 and $24 \mathrm{~h}$, in contrast to the continuous increase 233 of o-phosphorylethanolamine and taurine (Fig. 5). Latic acid was significantly upregulated at $2 \mathrm{~h}$ 234 but decreased to the control level at $24 \mathrm{~h}$; aspartic acid and glutamic acid were significantly 235 downregulated at $2 \mathrm{~h}$ but increased to the control level at $24 \mathrm{~h}$.

\section{Metabolic pathway of common metabolites}

237 KEGG pathway analysis was performed using MetaboAnalyst 3.0 software. Metabolic pathways were identified against the Danio rerio KEGG (zebrafish) library. Pathway topology analysis was performed based on the relative betweenness to calculate the important values. The metabolites were mapped onto 15 pathways for samples taken at $2 \mathrm{~h}$ (Table 2, Fig. 2S). Of these, the histidine metabolism pathway was significantly affected by thermal stress $(P<0.05)$. The dglutamine metabolism, alanine, aspartate and glutamate metabolism exhibited higher impact values and was also affected even though no significant difference was observed. A total of 15 pathways were obtained when metabolites were imported into KEGG for samples taken at $24 \mathrm{~h}$, and no pathway appeared to be significantly affected (Table 3). Interestingly, five pathways (glutathione metabolism, histidine metabolism, beta-alanine metabolism, nitrogen metabolism, alanine, aspartate and glutamate metabolism, aminoacyl-tRNA biosynthesis) showed significant changes between $2 \mathrm{~h}$ and $24 \mathrm{~h}$ (Table $3 S$ ).

\section{Discussion}

\section{Energy metabolism}

252 The present study found a positive correlation between the oxygen consumption rate of $S$.

253 subcrenata and the temperature of the surrounding environment. An increase in environmental 254 temperature will result in the elevation of physiological rates and biochemical reactions, such as 
255 activities of mitochondria and metabolic enzymes, and other oxygen- and energy-demanding 256 processes (Ivanina et al., 2013). The significant increase of oxygen consumption rate indicated 257 the upregulation of both aerobic metabolism and energy demand (Morley et al., 2012). Many 258 studies have indicated that the oxygen consumption rates of organisms typically increase with 259 temperature until reaching a threshold temperature (Shumway, 1982; Yukihira, Klumpp \& Lucas, 260 2000). Beyond this threshold, physiological rates can drastically decrease and anaerobic 261 metabolic end products accumulate (Sommer Klein \& Pörtner, 1997; Zhang et al., 2004). This 262 threshold is often referred to as the Arrhenius break temperature (ABT) (Jansen, Hummel \& 263 Bonga, 2009). In the present study, the oxygen consumption rate at $32{ }^{\circ} \mathrm{C}$ was always higher 264 than at other temperatures, suggesting that the ABT for S. subcrenata is higher than $32{ }^{\circ} \mathrm{C}$. 265 However, the higher mortality $(25 \%)$ at $32{ }^{\circ} \mathrm{C}$ suggests that such elevated heat stress might 266 exceed the self-regulation capacity of this species despite the 6-h acclimation the clams 267 experienced.

268 Variations in energy loss through respiration due to heat stress have been confirmed to influence 269 the energy balance (González et al. 2002). Ammonia production is a result of the deamination of 270 amino acids, and was also used to evaluate the energy loss of organisms when faced with 271 environmental stress (Wang et al., 2011; Shin, Chan \& Cheung, 2014). Evidence showed that 272 amino acids may be catabolized after being released from cells, resulting in the increase of blood 273 ammonia concentrations and external ammonia excretion rate (Pierce, 1982; Vitale and Friedl, 274 1984). Thus, the rate of ammonia-nitrogen excretion reflects the rate of protein catabolism 275 (Widdows, 1978). The increased ammonia excretion rate in the present study indicated that 276 amino acids might be catabolized, suggesting increased energy demand during heat stress. 277 The metabolomics approach, coupled with multivariate analysis, allowed the successful 278 investigation of metabolic changes in response to environmental stress (Cappello et al., 2013). 279 Multivariate analyses identified a clear separation between the control and heat stressed groups, 280 suggesting the existence of significant metabolic differences in the metabolic profile. Metabolic 281 profiling and functional analysis of key metabolic pathways provided an overview of the 282 metabolic status both before and after heat stress (Digilio et al., 2016; Hao et al., 2018). The 283 present data indicated that higher temperatures caused a wide array of changes in the metabolite 284 profiles of S. subcrenata. The metabolites with significant changes and their pathways differed 
285 greatly between clams that were exposed to heat-stress for $2 \mathrm{~h}$ and $24 \mathrm{~h}$, which could be due to 286 changes of metabolic substrates with prolonged stress exposure.

287 Amino acid metabolism

288 Many studies have highlighted that heat stress could influence both the energy balance and 289 energy homeostasis of aquatic invertebrates (Sokolova et al., 2012; Han et al., 2013). As shown 290 by the pathway enrichment analysis, most metabolites that showed significant changes 291 participated in amino acid metabolism (alanine, aspartate, glutamate, taurine, histidine, and beta292 alanine). Free amino acids account for a large fraction of the metabolome of marine invertebrates 293 (Cappello et al., 2013) and can be oxidized to supply energy in the Krebs cycle. When the oyster 294 (Crassostrea sikamea) was exposed to metal pollution, amino acids including threonine, alanine, 295 arginine, glutamate, $\beta$-alanine, aspartate, and glycine decreased significantly (Ji et al., 2016).

296 Exposure to $\mathrm{Cu}^{2+}$ could result in alterations of 25 metabolites involved in oxidative stress

297 responses and apoptosis processes in mussel Perna canaliculus (Nguyen et al., 2018a). In the 298 present study, the relative concentrations of both aspartic acid and glutamic acid were 299 significantly downregulated $2 \mathrm{~h}$ after heat stress, suggesting that these amino acids were possibly 300 oxidized. This downregulation is consistent with the significant increase of the oxygen 301 consumption rate. The oxidation of amino acids for energy expenditure is typically achieved via 302 deamination (Mcveigh et al., 2006), which would also explain the observed significant changes 303 of the ammonia excretion rate at $32{ }^{\circ} \mathrm{C}$. Taurine is also an osmolyte and plays an important role 304 in osmotic regulation (Preston, 1993; Cappello et al., 2013). Elevation of taurine levels indicates 305 a disorder in osmotic regulation of $S$. subcrenata under heat stress and similar responses have 306 been reported for the abalone Haliotis diversicolor (Lu et al., 2016).

307 In addition to the elevated aerobic metabolism, changes of anaerobic metabolites involved in the 308 energy metabolism were also observed in the present study. Glucose-6-phosphate lies at the start 309 of two major metabolic pathways: the glycolysis pathway and the pentose phosphate pathway.

310 Significant depletion of glucose-6-phosphate and activation of the glycolysis pathway suggested 311 that heat stress led to an enhancement of the anaerobic metabolism of S. subcrenata. Moreover, 312 the accumulation of lactic acid and Krebs cycle intermediate (pyruvic acid) suggested that the 313 Krebs cycle was disrupted by a switch towards anaerobic respiration. A similar result was also 314 found in mussel P. canaliculus infected Vibrio sp (Nguyen, 2018b; Nguyen \& Alfaro, 2019b) and 315 surf clam Crassula aequilatera exposed to thermal stress (Alfaro, Nguyen \& Mellow, 2019). 
316 When the ambient temperature exceeded the ABT, anaerobic metabolism in the limpet Cellana 317 toreuma was enhanced via the opine pathway to provide energy (Han et al., 2016). In stonefly 318 nymphs, accumulation of anaerobic metabolites (lactate, acetate, and alanine) was observed 319 when the animals reached critical temperature (Verberk et al., 2013). This transition to partial 320 anaerobiosis at high temperature is likely a compensation for insufficient aerobic energy 321 production and can be attributed to the limited capacity of oxygen uptake (Sokolova et al., 2012).

322 In ectotherms, when the ratio of oxygen supply to oxygen demand decreases and shortages of 323 oxygen arise, both the cardiac and respiration activities were insufficient to meet the elevated 324 oxygen demand at higher temperature (Frederich \& Pörtner, 2000; Verberk et al., 2013).

\section{Carbohydrate metabolism and lipid metabolism}

326 In the present study, the significant variation of phospho-ethanolamine, fatty acids, cytosine, and 327 adenine indicated that the lipid and nucleotide metabolisms were also involved into responses to heat stress. Lipids play both functional and structural roles in biological processes such as for energy supply and the maintenance of biological membranes (Lee, Park \& Lee, 2018). The oxidation of fatty acids produces acetyl CoA, which is an important intermediate metabolite of the Krebs cycle (Roznere et al., 2014). The significant decreases of azelaic acid, adipic acid, oleic acid, palmitic acid, and pentadecanoic acid suggest that the clams used lipid energy reserves for the production of acetyl CoA. Phospho-ethanolamine is an intermediate of the phospholipid metabolism. Ethanolamine is part of phosphatidylethanolamine (PE), which forms the cytomembrane of animal cells (McMaster, Tardi \& Choy, 1992). Ethanolamine is phosphorylated and enters the cytidine diphosphate pathway for PE synthesis (Chen et al., 2012). It has been reported that variations in temperature could result in membrane lipid remodeling in the blue mussel Mytilus edulis and the oyster Crassostrea virginica (Pernet et al., 2007, 2008). The present study found a significant upregulation of phospho-ethanolamine. This is inconsistent with the elevation of taurine, indicating that the membrane permeability might be influenced by exposure to heat stress. The intracellular concentrations of adenine nucleotides have been proposed as indicators of stress in aquatic organisms (Vetter, Hwang \& Hodson, 1986). In the present study, the concentrations of both adenine and cytosine significantly increased $2 \mathrm{~h}$ after exposure to $32{ }^{\circ} \mathrm{C}$, followed by increases of adenosine and cytidine-monophosphate at $24 \mathrm{~h}$, indicating enhanced nucleotide synthesis. However, no significant change was observed in the 
347 increased at $24 \mathrm{~h}$, while the thymidine concentration was significantly decreased, suggesting that

348 the nucleotide metabolism during heat stress requires further investigation.

349

\section{Conclusions}

351 In summary, the oxygen consumption and ammonia excretion rates were determined during

352

353

354

355

356

357

358

359

360

361

362

363

364

365

366

367

368

369

370

371

372

373

374

375

376

377

378

stress caused by different elevated temperatures in S. subcrenata. A GC/MS-based metabolomics approach was applied to assess changes of metabolites at $32{ }^{\circ} \mathrm{C}$. The results demonstrated that the clams increased their metabolic rates with elevated temperature, and mortality was observed under heat stress. Metabolite and functional analyses indicated that heat stress induced disturbances in energy metabolism, osmotic regulation, amino acid metabolism, carbohydrate metabolism, and lipid metabolism via different metabolic pathways. The present study provides an important contribution to the understanding of the impacts of heat stress on the clam $S$. subcrenata and elucidates the relationship between whole-organism responses and molecular metabolic dynamics. To better understand the physiological response of bivalves to environmental stresses, the integration of different omics approaches, including transcriptomics, proteomics and metabolomics, may be adopted in the future research.

\section{Acknowledgements}

We appreciate very much the assistance from Ms. Wenchao Liu and Mr. Peibo Bao in the lab measurement.

\section{References}

Alfaro AC, Nguyen TV, Mellow D. 2019. A metabolomics approach to assess the effect of storage conditions on metabolic processes of New Zealand surf clam (Crassula aequilatera). Aquaculture 498: 315-321 DOI 10.1016/j.aquaculture.2018.08.065

Alfaro AC, Young T. 2016. Showcasing metabolomic applications in aquaculture: a review. Reviews in Aquaculture 10:135-152 DOI 10.1111/raq.12152

Anestis A, Lazou A, Pörtner HO, Michaelidis B. 2007. Behavioral, metabolic, and molecular stress responses of marine bivalve Mytilus galloprovincialis during long-term acclimation at increasing ambient temperature. American Journal of Physiology. Regulatory, Integrative and Comparative Physiology 293: 911-921 DOI 10.1152/ajpregu.00124.2007 
379

380

381

382

383

384

385

386

387

388

389

390

391

392

393

394

395

396

397

398

399

400

401

402

403

404

405

406

407

408

409

410

411

412

413

414

415

416

417

418

419

420

421

422

Artigaud S, Lacroix C, Richard J, Flye-Sainte-Marie J, Bargelloni L, Pichereau V. 2015. Proteomic responses to hypoxia at different temperatures in the great scallop (Pecten maximus). Peerj 3(3): e871. DOI $10.7717 /$ peerj. 871

Artigaud S, Thorne MAS, Richard J, Lavaud R, Jean F, Flye-Sainte-Marie J, Peck LS, Pichereau V, Clark MS. 2014. Deep sequencing of the mantle transcriptome of the great scallop Pecten maximus. Marine Genomics 15: 3-4 DOI 10.1016/j.margen.2014.03.006

Cappello T, Mauceri A, Corsaro C, Maisano M, Parrino V, Paro G L, Giuseppe LP, Giuseppe M, Salvatore F. 2013. Impact of environmental pollution on caged mussels Mytilus galloprovincialis, using NMR-based metabolomics. Marine Pollution Bulletin 77(1-2): 132-139 DOI 10.1016/j.marpolbul.2013.10.019

Casas SM, Filgueira R, Lavaud R, Comeau LA, Peyre MKL, Peyre JFL. 2018. Combined effects of temperature and salinity on the physiology of two geographically-distant eastern oyster populations. Journal of Experimental Marine Biology and Ecology 506: 82-90 DOI 10.1016/j.jembe.2018.06.001

Cheng JS, Niu YH, Lu SH, Yuan YJ. 2012. Metabolome analysis reveals ethanolamine as potential marker for improving lipid accumulation of model photosynthetic organisms. Journal of Chemical Technology and Biotechnology 87: 1409-1418 DOI 10.1002/jctb.3759

Chen S, Zhang C, Xiong Y, Tian X, Liu C, Jeevithan E, Wu W. 2015. A GC-MS-based metabolomics investigation on scallop (Chlamys farreri) during semi-anhydrous living-preservation. Innovative Food Science \& Emerging Technologies 31: 185-195 DOI 10.1016/j.ifset.2015.07.003

Cheung SG, Lam SW. 1995. Effect of salinity, temperature and acclimation on oxygen consumption of Nassarius festivus (Powys, 1835) (Gastropoda: Nassariidae). Comparative Biochemistry and Physiology 111(4): 625-631 DOI 10.1016/0300-9629(95)00051-8

Davenport J, Davenport JL. 2005. Effects of shore height, wave exposure and geographical distance on thermal niche width of intertidal fauna. Marine Ecology Progress Series 292(1): 41-50 DOI 10.3354/meps292041

Digilio G, Sforzini S, Cassino C, Robotti E, Oliveri C, Marengo E, Musso D, Osella D, Viarengo A. 2016. Haemolymph from Mytilus galloprovincialis: response to copper and temperature challenges studied by ${ }^{1} \mathrm{H}-\mathrm{NMR}$ metabonomics. Comparative Biochemistry and Physiology Part C: Toxicology \& Pharmacology 183-184: 61-71 DOI 10.1016/j.cbpc.2016.02.003

Dowd WW, Somero GN. 2013. Behavior and survival of Mytilus congeners following episodes of elevated body temperature in air and seawater. Journal of Experimental Biology 216(3): 502-514 DOI 10.1242/jeb.076620

Ellis RP, Spicer JI, Byrne JJ, Sommer U, Viant MR, White DA, Widdicombe S. 2014. ${ }^{1} \mathrm{H}$ NMR metabolomics reveals contrasting response by male and female mussels exposed to reduced seawater $\mathrm{pH}$, increased temperature, and a pathogen. Environmental Science \& Technology 48: 7044-7052 https://doi.org/10.1021/es501601w

Ezgeta-Balić D, Rinaldi A, Peharda M, Prusina I, Montalto V, Niceta N, Sarà G. 2011. An energy budget for the subtidal bivalve Modiolus barbatus (Mollusca) at different temperatures. Marine Environmental Research 71: 79-85 DOI 10.1016/j.marenvres.2010.10.005

Frederich M, Pörtner HO. 2000. Oxygen limitation of thermal tolerance defined by cardiac and ventilatory performance in spider crab, Maja squinado. American Journal of Physiology. Regulatory, Integrative and Comparative Physiology 279(5): 1531-1538

https://doi.org/10.1152/ajpregu.2000.279.5.R1531

Peer) reviewing PDF | (2019:09:40921:1:0:NEW 29 Nov 2019) 
423

424

425

426

427

428

429

430

431

432

433

434

435

436

437

438

439

440

441

442

443

444

445

446

447

448

449

450

451

452

453

454

455

456

457

458

459

460

461

462

463

464

465
Frisk, M., Steffensen, J.F., Skov, P.V., 2013. The effects of temperature on specific dynamic action and ammonia excretion in pikeperch (Sander lucioperca). Aquaculture 404: 65-70 https://doi.org/10.1016/j.aquaculture.2013.04.005

González ML, López DA., Pérez MC, Castro JM. 2002. Effect of temperature on the scope for growth in juvenile scallops Argopecten purpuratus (Lamark, 1819). Aquaculture International 10(4): 339-348 DOI 10.1023/A:1022429209469

Guo C, Huang XY, Yang MJ, Wang S, Ren ST, Li H, Peng XX. 2014. GC/MS-based metabolomics approach to identify biomarkers differentiating survivals from death in crucian carps infected by Edwardsiella tarda. Fish \& Shellfish Immunology 39(2): 215-222 DOI 10.1016/j.fsi.2014.04.017

Han GD, Zhang S, Dong YW. 2016. Anaerobic metabolism and thermal tolerance: the importance of opine pathways on survival of a gastropod after cardiac dysfunction. Integrative Zoology 12: 361-370 DOI 10.1111/1749-4877.12229

Han GD, Zhang S, Marshall DJ, Ke CH, Dong YW. 2013. Metabolic energy sensors (AMPK and SIRT1), protein carbonylation and cardiac failure as biomarkers of thermal stress in an intertidal limpet: linking energetic allocation with environmental temperature during aerial emersion. Journal of Experimental Biology 216(17): 3273-3282 DOI 10.1242/jeb.084269

Hansen J, Sato M, Ruedy R, Lo K, Lea DW, Medina-Elizade M. 2006. Global temperature change. Proceedings of the National Academy of Sciences of the United States 103: 14288-14293 DOI 10.1073/pnas.0606291103

Hao R, Wang Z, Yang C, Deng Y, Zheng Z, Wang Q, Dong X. 2018. Metabolomic responses of juvenile pearl oyster Pinctada maxima to different growth performances. Aquaculture 491: 258-265 https://doi.org/10.1016/j.aquaculture.2018.03.050

Ivanina AV, Dickinson GH, Matoo OB, Bagwe R, Dickinson A, Beniash E, Sokolova IM. 2013. Interactive effects of elevated temperature and $\mathrm{CO}_{2}$ levels on energy metabolism and biomineralization of marine bivalves Crassostrea virginica and Mercenaria mercenaria. Comparative Biochemistry and Physiology. Part A, Molecular and Integrative Physiology 166(1): 101-111 DOI 10.1016/j.cbpa.2013.05.016

Jansen JM, Hummel H, Bonga SW. 2009. The respiratory capacity of marine mussels (Mytilus galloprovincialis) in relation to the high temperature threshold. Comparative Biochemistry and Physiology. Part A, Molecular and Integrative Physiology 153: 399-402 DOI 10.1016/j.cbpa.2009.03.013

Ji C, Li F, Wang Q, Zhao J, Sun Z, Wu H. 2016. An integrated proteomic and metabolomic study on the gender-specific responses of mussels Mytilus galloprovincialis, to tetrabromobisphenol A (TBBPA). Chemosphere 144: 527-539 DOI 10.1016/j.chemosphere.2015.08.052

Jin JE, Ahn CB, Je JY. 2018. Purification and characterization of antioxidant peptides from enzymatically hydrolyzed ark shell (Scapharca subcrenata). Process Biochemistry 72: 170-176 DOI 10.1016/j.procbio.2018.06.001

Juárez OE, Cruz FL, Leyva-Valencia I, López-Landavery E, García-Esquivel Z, Díaz F, Re-Araujo D, Vadopalas B, Galindo-Sánchez CE. 2018. Transcriptomic and metabolic response to chronic and acute thermal exposure of juvenile geoduck clams Panopea globosa. Marine Genomics 42: 1-13 DOI 10.1016/j.margen.2018.09.003

Lagerspetz KYH. 2006. What is thermal acclimation? Journal of Thermal Biology 31(4): 332-336 DOI 10.1016/j.jtherbio.2006.01.003

Peer] reviewing PDF | (2019:09:40921:1:0:NEW 29 Nov 2019) 
466

467

468

469

470

471

472

473

474

475

476

477

478

479

480

481

482

483

484

485

486

487

488

489

490

491

492

493

494

495

496

497

498

499

500

501

502

503

504

505

506

507

Lee MC, Park JC, Lee JS. 2018. Effects of environmental stressors on lipid metabolism in aquatic invertebrates. Aquatic Toxicology 200: 83-92 DOI 10.1016/j.aquatox.2018.04.016

Lim HJ, Kim BM, Hwang IJ, Lee JS, Choi IY, Kim YJ, Rhee JS. 2016. Thermal stress induces a distinct transcriptome profile in the pacific oyster Crassostrea gigas. Comparative Biochemistry and Physiology Part D Genomics and Proteomics 19: 62-70 DOI 10.1016/j.cbd.2016.06.006

Lu J, Shi Y, Wang S, Chen H, Cai S, Feng J. 2016. NMR-based metabolomic analysis of Haliotis diversicolor exposed to thermal and hypoxic stresses. Science of The Total Environment 545-546: 280-288 DOI 10.1016/j.scitotenv.2015.12.071

McMaster CR, Tardi PG, Choy PC. 1992. Modulation of phosphatidylethanolamine biosynthesis by exogenous ethanolamine and analogues in the hamster heart. Molecular and Cellular Biochemistry 116: 69-73 DOI 10.1007/BF01270571

Mcveigh A, Moore M, Allen JI, Dyke P. 2006. Lysosomal responses to nutritional and contaminant stress in mussel hepatopancreatic digestive cells: a modelling study. Marine Environmental Research, 62(Suppl): S433-S438 DOI 10.1016/j.marenvres.2006.04.021

Mishra P, Gong Z, Kelly BC. 2017. Assessing biological effects of fluoxetine in developing zebrafish embryos using gas chromatography-mass spectrometry based metabolomics. Chemosphere 188: 157167 DOI 10.1016/j.chemosphere.2017.08.149

Morley SA, Hirse T, Thorne MAS, Pörtner HO, Peck LS. 2012. Physiological plasticity, long term resistance or acclimation to temperature, in the Antarctic bivalve, Laternula elliptica. Comparative Biochemistry and Physiology. Part A, Molecular and Integrative Physiology 162(1): 16-21 DOI 10.1016/j.cbpa.2012.01.009

Nakamura Y. 2005. Suspension feeding of the ark shell Scapharca subcrenata as a function of environmental and biological variables. Fisheries Science 71 (4): 875-883 DOI 10.1111/j.14442906.2005.01040.x

Nguyen TV, Alfaro AC, Merien F, Lulijwa R, Young T. 2018a. Copper-induced immunomodulation in mussel (Perna canaliculus) haemocytes. Metallomics 10: 965-978 DOI 10.1039/C8MT00092A

Nguyen TV, Alfaro AC, Merien F, Young T, Grandiosa R. 2018b. Metabolic and immunological responses of male and female New Zealand Greenshell ${ }^{\text {TM }}$ mussels (Perna canaliculus) infected with Vibrio sp. Journal of Invertebrate Pathology 157: 80-89

Nguyen TV, Alfaro AC, Young T, Merien F. 2018c. Tissue-specific immune responses to Vibrio sp. infection in mussels (Perna canaliculus): A metabolomics approach. Aquaculture 500: 118-125 DOI 10.1016/j.aquaculture.2018.09.061

Nguyen TV, Alfaro AC, Young T, Ravi S, Merien F. 2018d. Metabolomics study of immune responses of New Zealand greenshell ${ }^{\mathrm{TM}}$ mussels (Perna canaliculus) infected with pathogenic Vibrio sp. Marine Biotechnology 20: 396-409 DOI 10.1007/s10126-018-9804-x.

Nguyen TV, Alfaro AC. 2019a. Applications of omics to investigate responses of bivalve haemocytes to pathogen infections and environmental stress. Aquaculture DOI 10.1016/j.aquaculture.2019.734488

Nguyen TV, Alfaro AC. 2019b. Targeted metabolomics to investigate antimicrobial activity of itaconic acid in marine molluscs. Metabolomics 15: 97 DOI 10.1007/s11306-019-1556-8

Nie HT, Liu LH, Huo ZM, Chen P, Ding JF, Yang F, Yan XW. 2017. The HSP70 gene expression responses to thermal and salinity stress in wild and cultivated Manila clam Ruditapes philippinarum. Aquaculture 470: 149-156 DOI 10.1016/j.aquaculture.2016.12.016 
508

509

510

511

512

513

514

515

516

517

518

519

520

521

522

523

524

525

526

527

528

529

530

531

532

533

534

535

536

537

538

539

540

541

542

543

544

545

546

547

548

549

550

551

Pernet F, Tremblay R, Comeau L, Guderley H. 2007. Temperature adaptation in two bivalve species from different thermal habitats: energetics and remodelling of membrane lipids. Journal of Experimental Biology 210: 2999-3014 DOI 10.1242/jeb.006007

Pernet F, Tremblay R, Redjah I, Sevigny JM, Gionet C. 2008. Physiological and biochemical traits correlate with differences in growth rate and temperature adaptation among groups of the eastern oyster Crassostrea virginica. Journal of Experimental Biology 211: 969-977 DOI 10.1242/jeb.014639

Pierce S. 1982. Invertebrate cell volume control mechanisms: a coordinated use of intracellular amino acids and inorganic ions as osmotic solute. The Biological Bulletin 163: 405-419 DOI $10.2307 / 1541452$

Pörtner HO. 2010. Oxygen- and capacity-limitation of thermal tolerance: amatrix for integrating climaterelated stressor effects in marine ecosystems. Journal of Experimental Biology 213: 881-893. DOI $10.1242 /$ jeb.037523

Pörtner HO, Bennett AF, Bozinovic F, Clarke A, Lardies MA, Lucassen M, Pelster B, Schiemer F, Stillman JH. 2006. Trade-offs in thermal adaptation: the need for a molecular to ecological integration. Physiological and Biochemical Zoology 79: 295-313 DOI 10.1086/499986

Preston RL. 1993. Transport of amino-acids by marine-invertebrates. Journal of Experimental Zoology 265: 410-421 DOI 10.1002/jez.1402650410

Roznere I, Watters GT, Wolfe BA, Daly M. 2014. Nontargeted metabolomics reveals biochemical pathways altered in response to captivity and food limitation in the freshwater mussel Amblema plicata. Comparative Biochemistry and Physiology Part D Genomics and Proteomics 12: 53-60 DOI 10.1016/j.cbd.2014.09.004

Sara G. 2008. Effect of salinity and temperature on feeding physiology and scope for growth of an invasive species (Brachidontes pharaonis - Mollusca: Bivalvia) within the Mediterranean sea. Journal of Experimental Marine Biology and Ecology 363: 130-136 DOI 10.1016/j.jembe.2008.06.030

Saucedo PE, Ocampo L, Monteforte M, Bervera H. 2004. Effect of temperature on oxygen consumption and ammonia excretion in the Calafia mother-of-pearl oyster, Pinctada mazatlanica (Hanley, 1856). Aquaculture 229: 377-387 DOI 10.1016/s0044-8486(03)00327-2

Shin PK, Chan CS, Cheung SG. 2014. Physiological energetics of the fourth instar of Chinese horseshoe crabs (Tachypleus tridentatus) in response to hypoxic stress and re-oxygenation. Marine Pollution Bulletin 85(2): 522-525 DOI 10.1016/j.marpolbul.2013.10.023

Shumway SE. 1982. Oxygen consumption in oysters: an overview. Marine Biology Letters 3: 1-23

Sobral P, Widdows J. 1997. Effects of elevated temperatures on the scope for growth and resistance to air exposure of the clam Ruditapes decussatus (L), from southern Portugal. Scientia Marina 61: 163-171 DOI 10.1023/A:1018435711128

Sokolova IM, Frederich M, Bagwe R, Lannig G, Sukhotin AA. 2012. Energy homeostasis as an integrative tool for assessing limits of environmental stress tolerance in aquatic invertebrates. Environmental Research 79: 1-15 DOI 10.1016/j.marenvres.2012.04.00

Solorzano L. 1969. Determination of ammonia in natural waters by the phenolhypochlorite method. Limnology and Oceanography 14: 799-801 DOI 10.4319/1o.1969.14.5.0799

Sommer A, Klein B, Pörtner HO. 1997. Temperature induced anaerobiosis in two populations of the polychaete worm Arenicola marina (L.). Journal of Comparative Physiology B 167: 25-35 DOI $10.1007 / \mathrm{s} 003600050044$

Stickland J, Parsons T. 1968. A practical handbook of seawater analysis. Fisheries Research Board of Canada Bulletin 167: 1-11 DOI 10.1002/iroh.19700550118 
552

553

554

555

556

557

558

559

560

561

562

563

564

565

566

567

568

569

570

571

572

573

574

575

576

577

578

579

580

581

582

583

584

585

586

587

588

589

590

591

592

593

594

Tsugawa H, Tsujimoto Y, Arita M, Bamba T, Fukusaki E. 2011. GC/MS based metabolomics: development of a data mining system for metabolite identification by using soft independent modeling of class analogy (SIMCA). BMC Bioinformatics 12: 131 DOI 10.1186/1471-2105-12-131

Verberk WCEP, Sommer U, Davidson RL, Viant MR. 2013. Anaerobic metabolism at thermal extremes: a metabolomic test of the oxygen limitation hypothesis in an aquatic insect. Integrative and Comparative Biology 53(4): 609-619 DOI 10.1093/icb/ict015

Vetter RD, Hwang HM, Hodson RE. 1986. Comparison of glycogen and adenine nucleotides as indicators of metabolic stress in mummichogs. Transactions of the American Fisheries Society 115(1): 47-51 DOI 10.1577/1548-8659(1986)115<47:cogaan>2.0.co;2

Vitale MA, Friedl FE. 1984. Ammonia production by the freshwater bivalve Elliptio buckleyi (Lea): intact and monovalve preparations. Comparative Biochemistry and Physiology 77: 113-116 DOI 10.1016/0300-9629(84)90021-5

Wang YJ, Hu M, Wong WH, Shin PK, Cheung SG. 2011. The combined effects of oxygen availability and salinity on physiological responses and scope for growth in the green-lipped mussel Perna viridis. Marine Pollution Bulletin 63(5-12): 255-261 DOI 10.1016/j.marpolbul.2011.02.004

Wang YJ, Li L, Hu M, Lu W. 2015. Physiological energetics of the thick shell mussel Mytilus coruscus exposed to seawater acidification and thermal stress. Science of The Total Environment 514: 261-272 DOI 10.1016/j.scitotenv.2015.01.092

Wei L, Wang Q, Ning XX, Mu CK, Wang CL, Cao RW, Wu HF, Cong M, Li F, Ji CL, Zhao JM. 2015. Combined metabolome and proteome analysis of the mantle tissue from pacific oyster Crassostrea gigas exposed to elevated $p \mathrm{CO}_{2}$. Comparative Biochemistry and Physiology Part D Genomics and Proteomics 13: 16-23 DOI 10.1016/j.cbd.2014.12.001

Widdows J. 1978. Physiological indices of stress in Mytilus edulis. Journal of the Marine Biological Association of the UK 58: 125-142 DOI 10.1017/s0025315400024450

Yang CY, Gao Q, Liu C, Wang LL, Zhou Z, Gong CH, Zhang AG, Zhang H, Qiu LM, Song LS. 2017. The transcriptional response of the pacific oyster, Crassostrea gigas, against acute heat stress. Fish \& Shellfish Immunology 68: 132-143 DOI 10.1016/j.fsi.2017.07.016

You ZJ, Jiao HF. 2011. Research on Xiangshan Bay ecological environmental protection and restoration technology. China Ocean Press 9. (in Chinese)

Young T, Alfaro AC. 2018. Metabolomic strategies for aquaculture research: a primer. Reviews in Aquaculture 10: 26-56 DOI 10.1111/raq.12146

Yukihira H, Klumpp DW, Lucas JS. 2000. Comparative effects of temperature on suspension feeding and energy budgets of the pearl oysters Pinctada margaritifera and P. maxima. Marine Ecology-Progress Series 195: 179-188 DOI 10.3354/meps 170119

Zange J, Pörtner HO, Grieshaber MK. 1989. The anaerobic energy metabolism in the anterior byssus retractor muscle of Mytilus edulis during contraction and catch. Journal of Comparative Physiology B 159: 349-358 DOI 10.1007/bf00691515

Zhang JH, Fang JG, Hawkins AJS, Pascoe PL. 2004. The effect of temperature on clearance rate and oxygen consumption of scallops, Chlamys farreri. Journal of Shellfish Research 23(3): 715-721

Zhang X, Shi JL, Sun YL, Habib YJ, Yang HP, Zhang ZP, Wang YL. 2019. Integrative transcriptome analysis and discovery of genes involving in immune response of hypoxia/thermal challenges in the small abalone Haliotis diversicolor. Fish \& Shellfish Immunology 84: 609-626 DOI 10.1016/j.fsi.2018.10.044

Peer] reviewing PDF | (2019:09:40921:1:0:NEW 29 Nov 2019) 
595 Zhang Y, Wu H, Wei L, Xie Z, Guan B. 2017. Effects of hypoxia in the gills of the manila clam

596 Ruditapes philippinarum using NMR-based metabolomics. Marine Pollution Bulletin 114(1): 84-89

597 DOI 10.1016/j.marpolbul.2016.08.066 
Figure 1

Oxygen consumption rates of $S$. subcrenata after exposed to different temperatures.

Asterisks indicate significant differences ( $P<0.05$; ** $P<0.01$ ) between the stressed and control group.

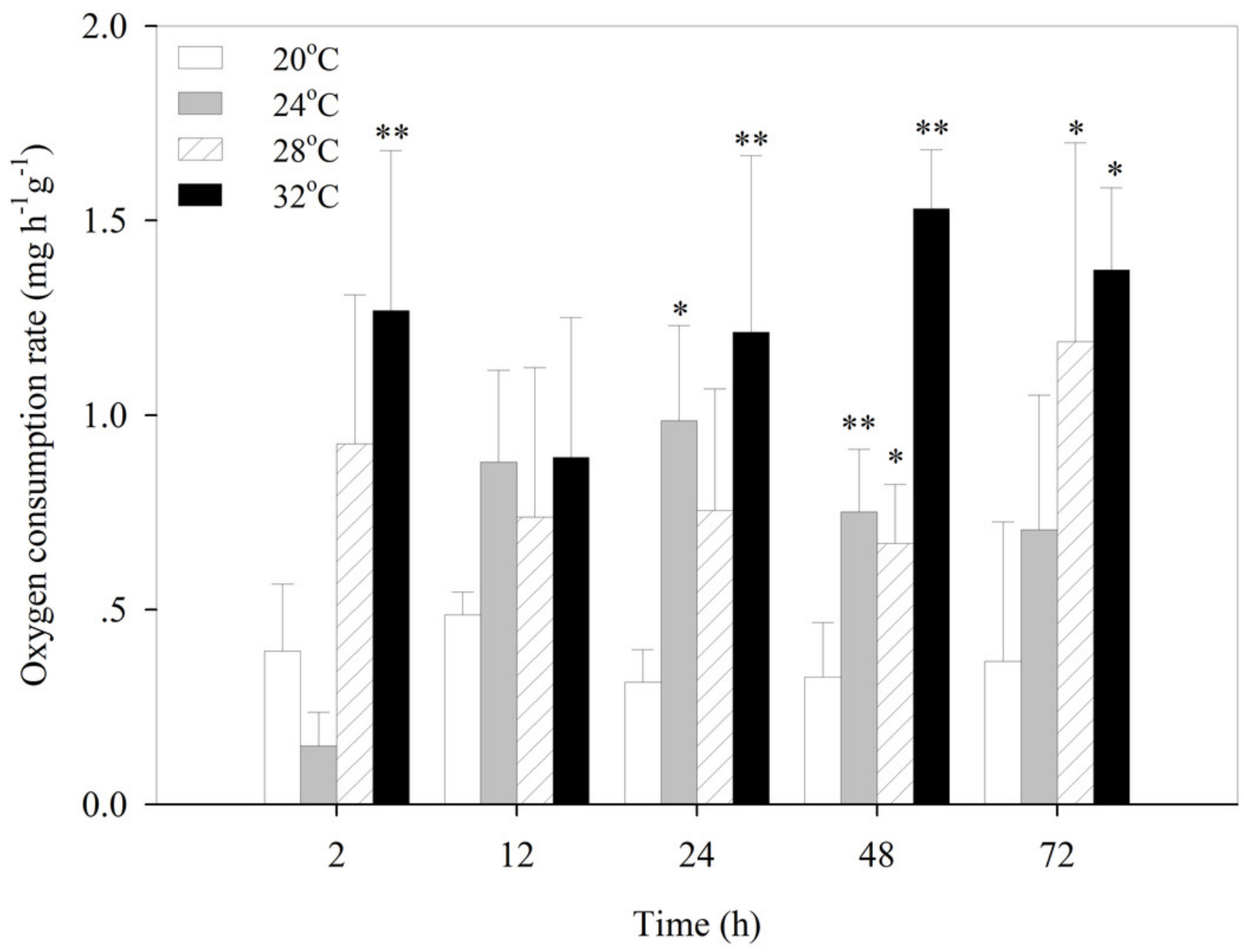


Figure 2

Ammonia excretion rates of $S$. subcrenata after exposed to different temperatures.

Asterisks indicate significant differences $\left(* P<0.05 ;{ }^{* *} P<0.01\right)$ between the stressed and control group.

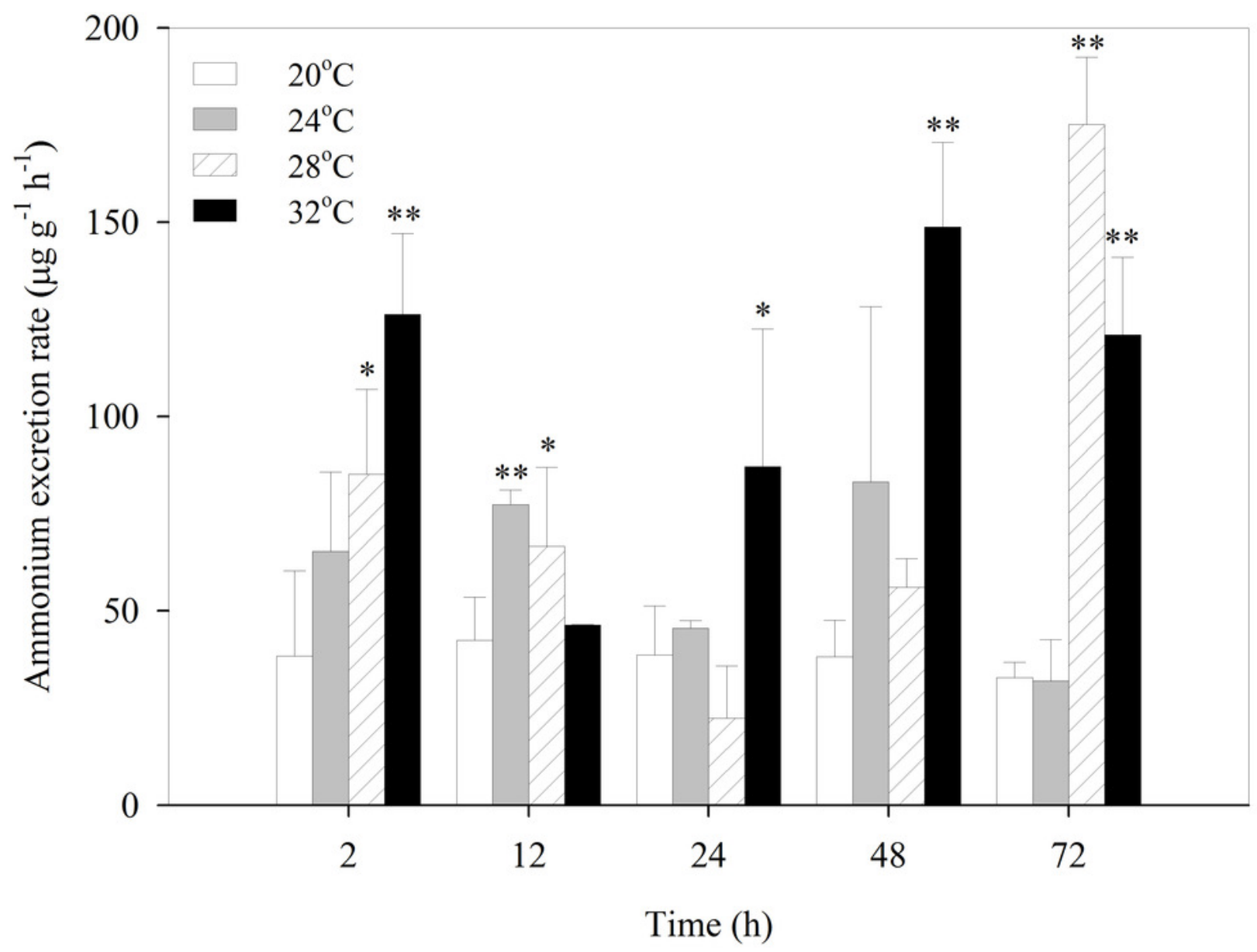


Figure 3

The score plot of PCA.

QC is the quality control sample. M- 0 is the control group, and $\mathrm{M}-2$ and $\mathrm{M}-24$ are the samples taken at $2 \mathrm{~h}$ and $24 \mathrm{~h}$, respectively. The Hotelling ellipse indicating $95 \%$ confidence interval.

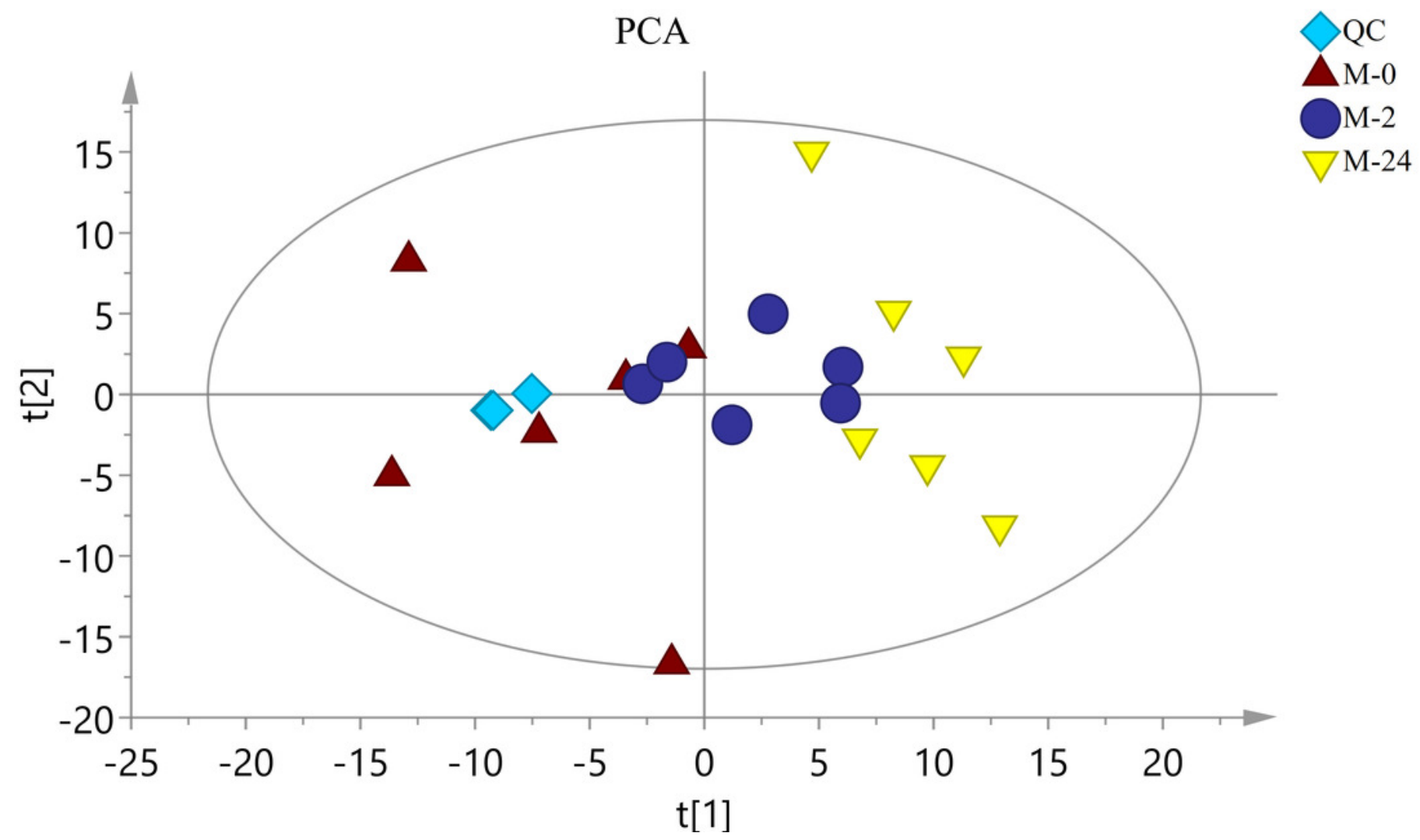


Figure 4

PLS-DA and OPLS-DA score plots derived from metabolite profiles of $S$. subcrenata.

$\mathrm{M}-0$ is the control group, and $\mathrm{M}-2$ and $\mathrm{M}-24$ are the samples taken at $2 \mathrm{~h}$ and $24 \mathrm{~h}$, respectively.
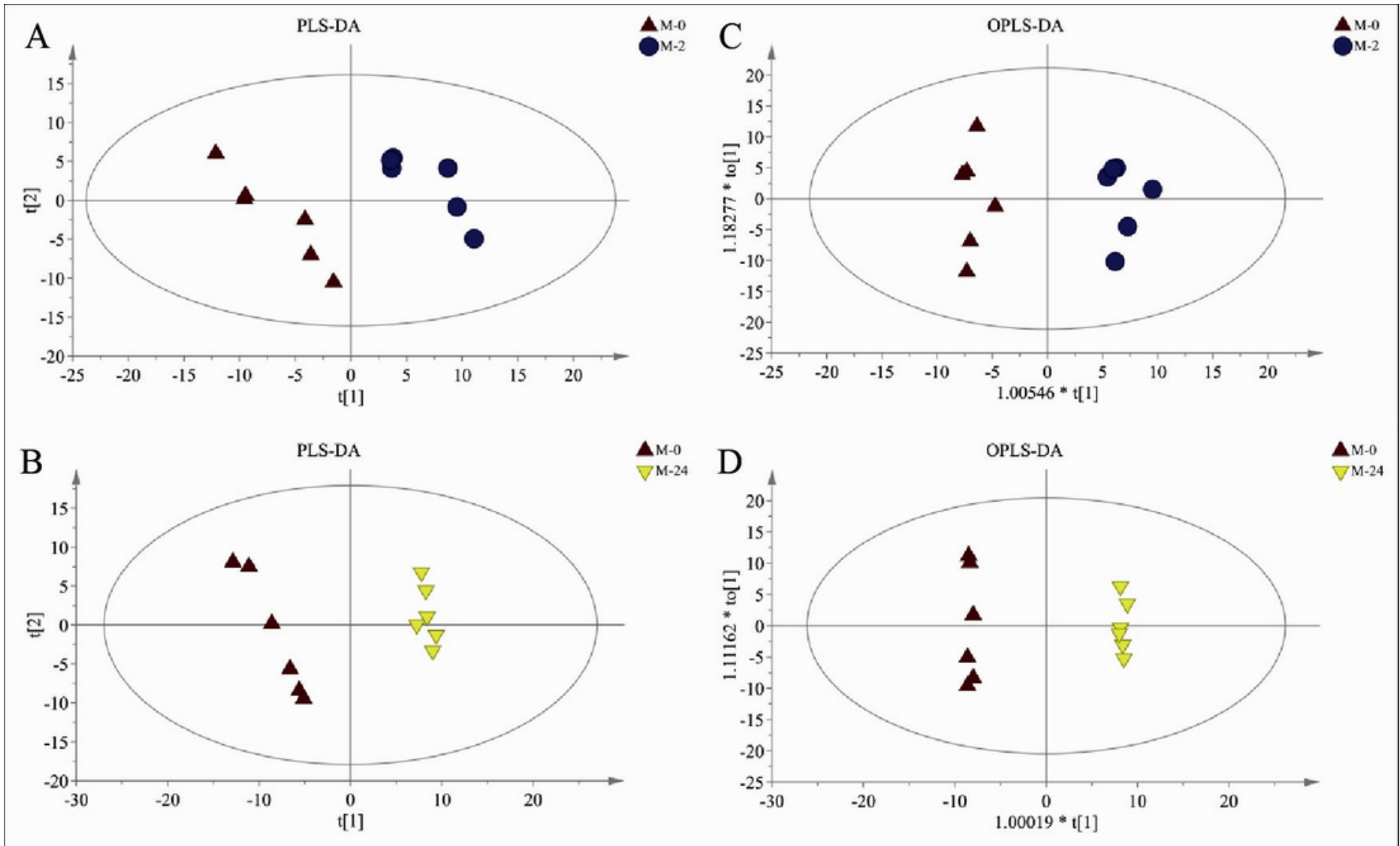
Figure 5

Metabolite levels of metabolites in the mantle of S. subcrenata after exposure to $32{ }^{\circ} \mathrm{C}$.

(A): glucose-6-phosphate, (B): 0-phosphorylethanolamine, (C): taurine, (D): lactic acid, (E): aspartic acid, and (F): glutamic acid. 

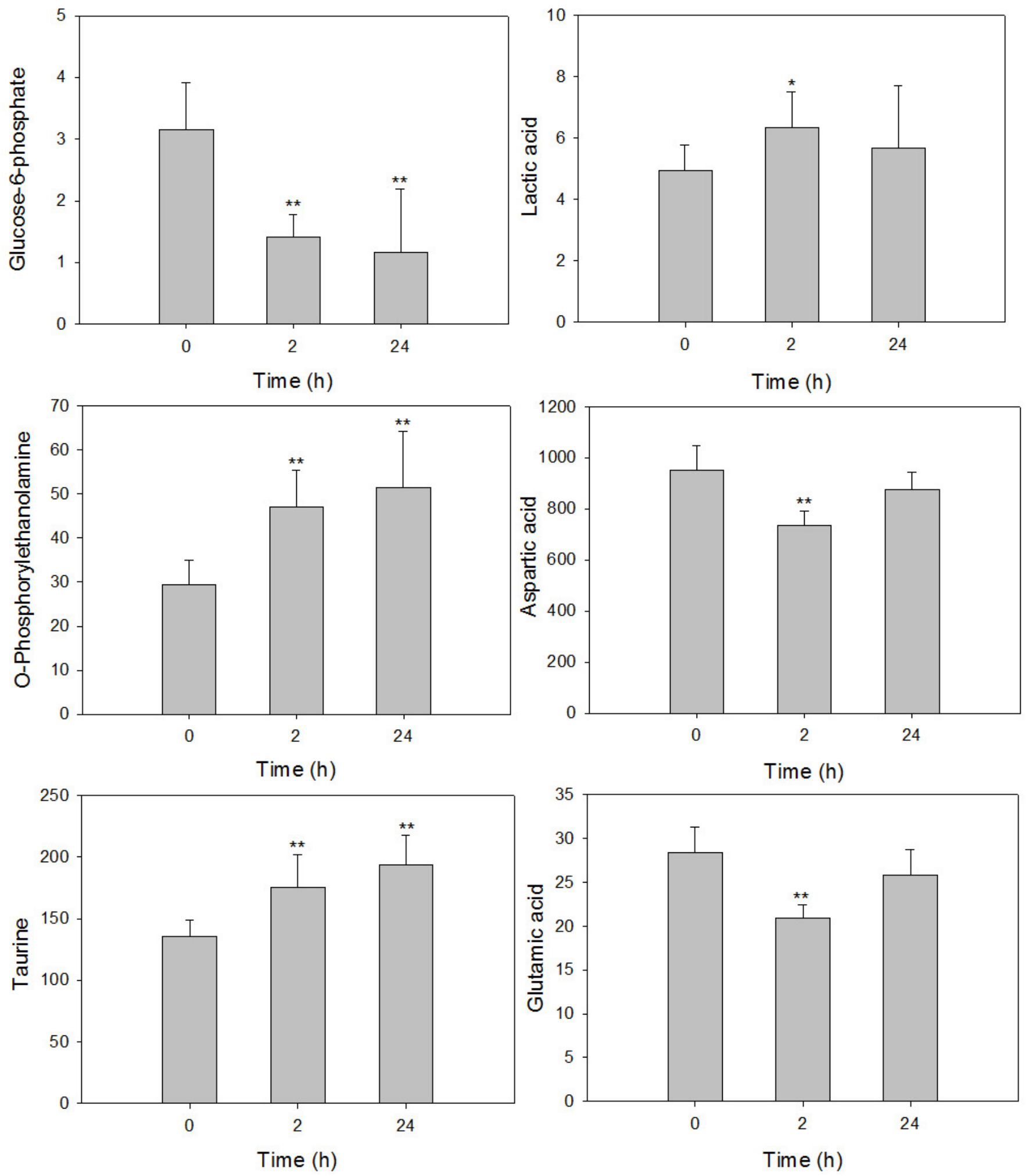


\section{Table $\mathbf{1}$ (on next page)}

Multivariate analysis of metabolite profiles of $S$. subcrenata after exposure to heat stress.

Two principal components for PCA model, two principal components for PLS-DA model, and one principal component and one orthogonal component for OPLS-DA model were used. 


\begin{tabular}{|c|c|c|c|c|c|c|c|c|c|}
\hline \multirow{2}{*}{$\begin{array}{l}\text { Model } \\
\text { type }\end{array}$} & \multicolumn{4}{|c|}{$0-2 \mathrm{~h}$} & \multicolumn{5}{|c|}{$0-24 \mathrm{~h}$} \\
\hline & $\overline{R^{2} X(\text { cun }}$ & ${ }^{2} Y$ (cun & $\overline{Q^{2} \text { (cum) }}$ & $Q^{2}$ & $\overline{R^{2} X(\text { cun }}$ & ${ }^{2} Y($ cum & $\overline{Q^{2} \text { (cum) }}$ & $R^{2}$ & $Q^{2}$ \\
\hline PLS-DA & 0.3 & 0.97 & 0.445 & & 0.36 & 0.991 & 0.841 & & \\
\hline OPLS-DA & 0.3 & 0.97 & 0.381 & $0.963-0.033$ & 0.468 & 0.999 & 0.833 & 0.993 & -0.003 \\
\hline
\end{tabular}

1 


\section{Table 2 (on next page)}

Pathway enrichment analysis of the metabolites at $2 \mathrm{~h}$ after exposed to $32{ }^{\circ} \mathrm{C}$ 


\begin{tabular}{lccc}
\hline \multicolumn{1}{c}{ Pathway } & $\boldsymbol{P}$ & $-\boldsymbol{l o g}(\boldsymbol{P})$ & Impact \\
\hline Histidine metabolism & 0.026555 & 3.62 & 0.0 \\
Alanine, aspartate and glutamate metabolism & 0.071896 & 2.63 & 0.45253 \\
D-Glutamine and D-glutamate metabolism & 0.090061 & 2.41 & 1.0 \\
Taurine and hypotaurine metabolism & 0.12386 & 2.09 & 0.2 \\
Nitrogen metabolism & 0.15645 & 1.86 & 0.0 \\
Arginine and proline metabolism & 0.19022 & 1.66 & 0.09612 \\
Nicotinate and nicotinamide metabolism & 0.23292 & 1.46 & 0.0 \\
beta-Alanine metabolism & 0.2616 & 1.34 & 0.0 \\
Sphingolipid metabolism & 0.32888 & 1.11 & 0.01504 \\
Pyruvate metabolism & 0.34161 & 1.07 & 0.0 \\
Butanoate metabolism & 0.34161 & 1.07 & 0.0 \\
Aminoacyl-tRNA biosynthesis & 0.35866 & 1.0254 & 0.0 \\
Glycolysis or Gluconeogenesis & 0.39025 & 0.94097 & 0.0 \\
Glutathione metabolism & 0.39025 & 0.94097 & 0.02968 \\
Porphyrin and chlorophyll metabolism & 0.40186 & 0.91166 & 0.0 \\
\hline
\end{tabular}




\section{Table 3(on next page)}

Pathway enrichment analysis of the metabolites at $24 \mathrm{~h}$ after exposed to $32^{\circ} \mathrm{C}$ 


\begin{tabular}{lccc}
\hline \multicolumn{1}{c}{ Pathway } & $\boldsymbol{P}$ & $-\log (\boldsymbol{P})$ & Impact \\
\hline Glyoxylate and dicarboxylate metabolism & 0.18143 & 1.7069 & 0.03704 \\
Synthesis and degradation of ketone bodies & 0.19888 & 1.615 & 0.0 \\
Cyanoamino acid metabolism & 0.23371 & 1.4537 & 0.0 \\
Butanoate metabolism & 0.2462 & 1.4016 & 0.0 \\
Taurine and hypotaurine metabolism & 0.26706 & 1.3203 & 0.2 \\
Biosynthesis of unsaturated fatty acids & 0.2724 & 1.3005 & 0.0 \\
Alanine, aspartate and glutamate metabolism & 0.27904 & 1.2764 & 0.0 \\
Nitrogen metabolism & 0.32952 & 1.1101 & 0.0 \\
Riboflavin metabolism & 0.38674 & 0.94999 & 0.16667 \\
Glycine, serine and threonine metabolism & 0.39216 & 0.93608 & 0.0 \\
Valine, leucine and isoleucine biosynthesis & 0.43916 & 0.82289 & 0.0 \\
Histidine metabolism & 0.46369 & 0.76853 & 0.2381 \\
beta-Alanine metabolism & 0.50963 & 0.67406 & 0.0 \\
Selenoamino acid metabolism & 0.53113 & 0.63275 & 0.0 \\
Pyrimidine metabolism & 0.53865 & 0.61869 & 0.08825 \\
\hline
\end{tabular}

